\title{
Rapid and Reliable Elimination System for Radioactive Cesium Using Magnetic Nanocomposites
}

\author{
Y. NAMIKI \\ Institute of Clinical Medicine and Research, The Jikei University School of Medicine, \\ 163-1 Kashiwa-shita, Kashiwa, Chiba 277-8567, Japan
}

\begin{abstract}
We have devised the rapid elimination system for the contaminated radioactive cesium using magnetic nanocomposites. The Great East Japan Earthquake hit caused a serious meltdown of the overheated fuel rods and the release of radioactive chemicals into the environment. Until now, fuel rods have been cooled using seawater to control its temperature, therefore huge amount of waste water containing high concentrations of radioactive cesium have been continuously generated. On the other hand, radioactive cesium is easily condensed in the fly ash originating from incineration of garbage. The garbage incineration plant is overflowing with the fly ash which cannot be discarded (when the radioactivity of fly ash exceeds $8000 \mathrm{~Bq} / \mathrm{kg}$, we cannot discard it as a usual manner). Prussian blue is known as an effective eliminator of radioacitive cesium from seawater and fly ash slurry, however complete and rapid collection of Prussian blue dispersed in water is very difficult. Recently, we have developed a novel form of magnetically guidable Prussian blue coated magnetic nanocomposite clusters via the application of nanotechnology for drug delivery system. Using this type of nanocomposites under magnetic field, we have confirmed that $99.9 \%$ and over $80 \%$ of cesium were rapidly removed from seawater and fly ash, respectively.
\end{abstract}

Key Words: Magnetic elimination, Radioactive cesium, Magnetic nanocomposites

\section{INTRODUCTION}

We have developed a functional nanoparticle-mediated magnetic elimination system which will be a potential approach for the rapid removal of hazardous carcinogenic radioactive cesium from environment. On March 11, 2011, the Great East Japan Earthquake caused a serious meltdown of the fuel rods at the Fukushima Daiichi nuclear power station, and finally, huge amounts of radioactive chemicals have leaked and spread over a large area. U.S. National Cancer Institute at the National Institutes of Health reported that cesium-137 $\left(\mathrm{Cs}^{137}\right)$ and iodine-131 $\left(\mathrm{I}^{131}\right)$ are two major radioisotopes which induce the cancer most frequently among the isotopes which are released by the accident of nuclear power plant. From a view point of long-terms effects, $\mathrm{Cs}^{137}$ has much longer half-life than $\mathrm{I}^{131}$ (Cs ${ }^{137}: 30$ years; $\mathrm{I}^{131}: 8$ days), therefore, 137Cs remains about $80 \%$ of radioactivity at even 10 years after the release. Cesium is known to have a biological behavior profile similar to that of potassium and cesium accumulates in the muscle tissues of fish and animals, and through food chains the cesium is concentrated in the body of apex predators. A blue pigment Prussian blue has been used as an antidote for the internal exposure of radioactive cesium. It is not easy to completely collect dispersed Prussian blue nanoparticles, so we have devised the Prussian-coated magnetic nanoparticles which can be easily accumulated by the magnetic field.

\section{EXPERIMENTAL}

For biomedical application, we have developed various kinds of magnetically guided drug delivery system for cancer (1-6, 8). Using these nanoparticle technologies, we have coated the Prussian blue on the surface of magnetic nanoparticles. Initially magnetic nanoparticles were modified with cationic polymer, poly (diaryldimethylammonium chloride) (PDDA). Then anionic Prussian blue was bound to PDDA-modified magnetic nanoparticles and Prussian blue-coated magnetic nanoparticles were obtained (7). Sequentially, using the combination of this magnetic nanoparticles and neodymium magnets, we have investigated the degree of magnetic elimination of contaminated cesium from sea water, serum, milk and fly ashes.

\section{RESULTS AND DISCUSSION}

Through the magnetic separation of this type of nanocomposites, we have confirmed that $99.9 \%$ of experimentally added non-radioactive cesium was rapidly removed from sea water, fetal calf serum and milk (Fig. 1). Using Na-I crystal 


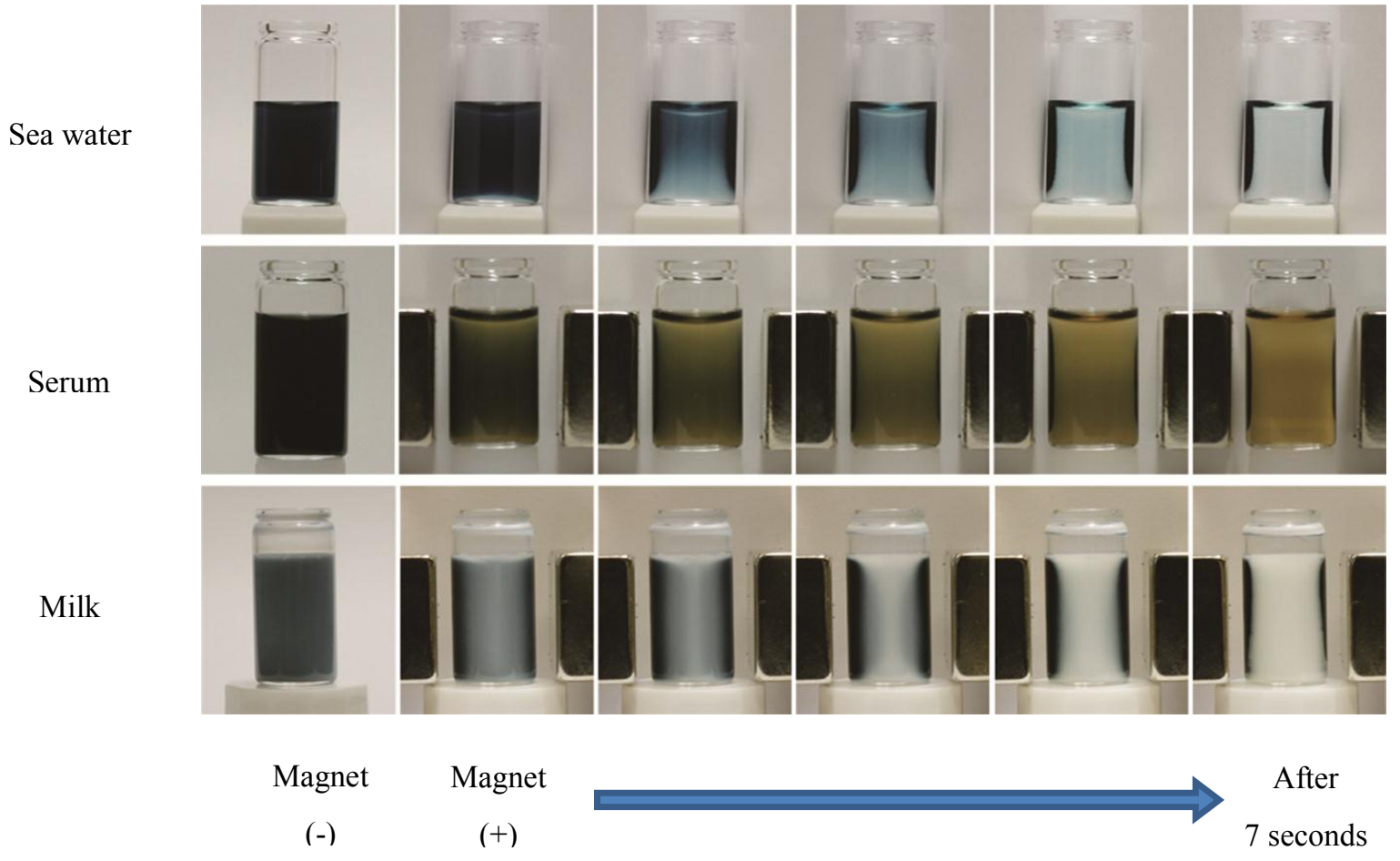

Fig. 1 Examples of solid-liquid separation.

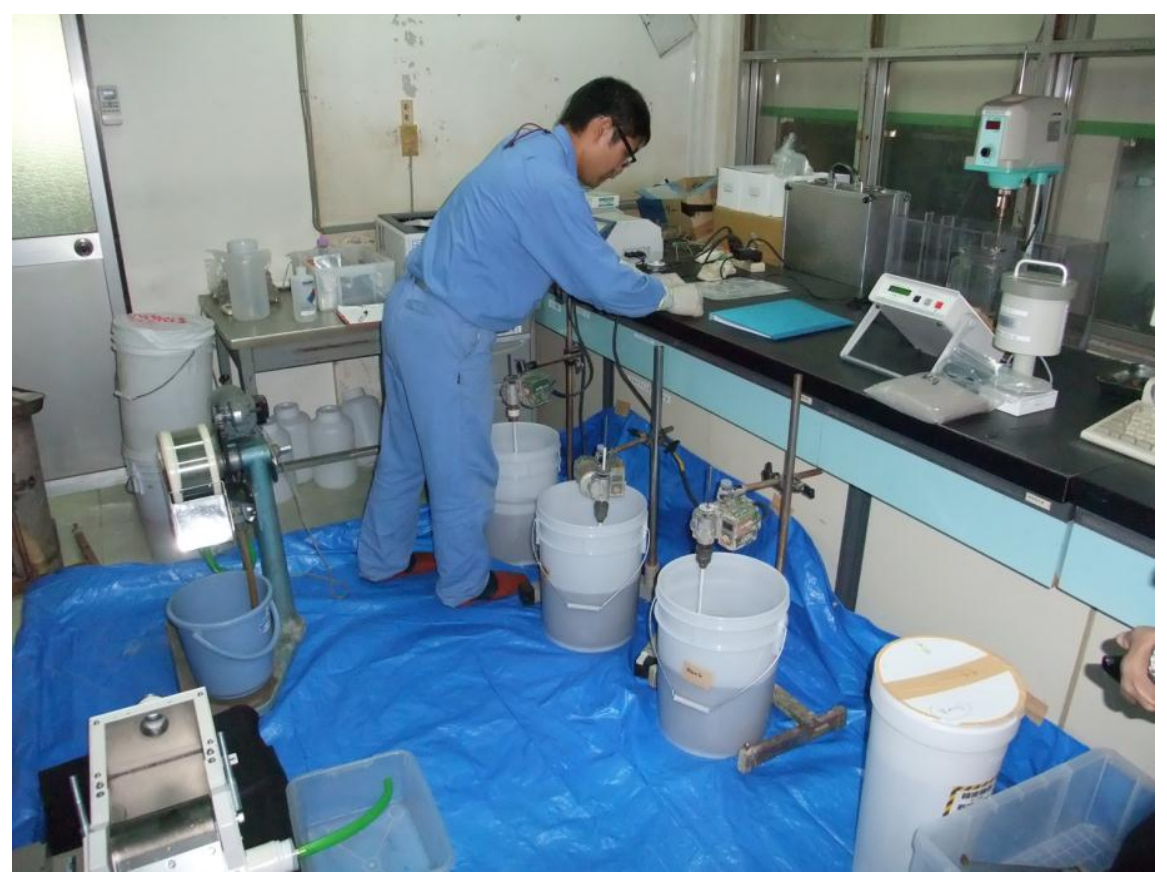

Fig. 2 Examples of solid-solid separation (fly ash). 
scintillator, we confirmed that over $80 \%$ of radioactive cesium was removed from fly ash slurry containing $40 \mathrm{~g}$ of fly ash and $400 \mathrm{~mL}$ of water (Fig. 2, 3). Importantly, milk contains large sized fat globules which does not pass through a fine membrane filter, so regular decontaminants powder cannot be separated using such filer membrane after the mix with milk. Taken together, this type of the magnetic nanoparticles displayed rapid and reliable elimination of cesium from various samples, and were useful for not only solid-liquid separation but also solid-solid separation.

Pre-treatment
$8186 \mathrm{~Bq} / \mathrm{kg}$
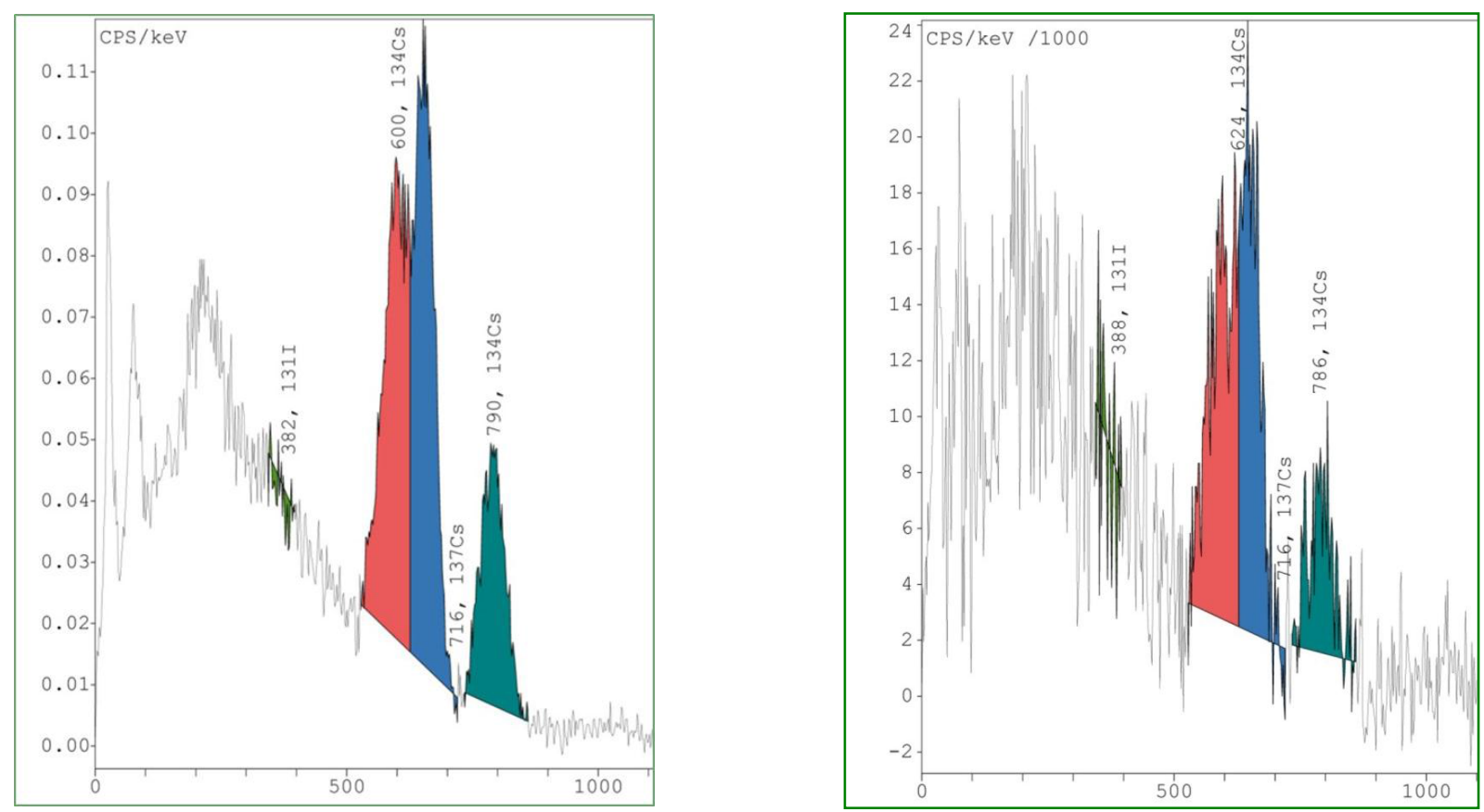

Fig. 3 The degree of radioactive cesium of fly ashes between pre-treatment and post-treatment.

\section{CONCLUSION}

By this type of magnetic nanoparticles, water-soluble radioactive cesium can be easily decontaminated. Therefore if new technology for increasing the elution amount of cesium is developed, application field of the magnetic decontamination will be extended.

\section{ACKNOWLEDGMENTS}

We dedicate this work to the late T. Terada, the late K. Nariai, and the many people who suffered in the March 11 disaster. This work was supported by a Funding Program for the Next Generation of World-Leading Researchers (LS114) from the JSPS, an Industrial Technology Research Grant (08C46049a) from the NEDO of Japan, a DOWA Technical Foundation, an Iketani Science and Technology Foundation of Japan, and a Hamaguchi Foundation for the Advancement of Biochemistry.

\section{REFERENCES}

[1] Namiki Y, Namiki T, Yoshida H, Ishii Y, Koido S, Tada N, et al., Nature Nanotechnology, 4, 598 (2009).

[2] Fuchigami T, Kawamura R, Kitamoto Y, Nakagawa M and Namiki Y, Langmuir, 27, 2923 (2011).

[3] Namiki Y, Fuchigami T, Tada N, Kawamura R, Matsunuma S, Kitamoto Y, et al., Acc Chem Res. 44, 1080 (2011). 
[4] Namiki Y, Matsunuma S, Inoue T, Koido S, Tada N, Kuse Y, et al., “Nanocrystal”, INTECH, Rijeka, Croatia, 2011 . p.349.

[5] Fuchigami T, Kawamura R, Kitamoto Y, Nakagawa M and Namiki Y, Biomater. 33, 1682 (2012).

[6] Fuchigami T, Kitamoto Y and Namiki Y, Biomater. 2, 313 (2012).

[7] Namiki Y, Namiki T, Ishii Y, Koido S, Nagase Y, Tada N, Pharm Res. 29, 1404 (2012).

[8] Namiki Y, Methods Mol. Biol. 948, 243 (2013). 